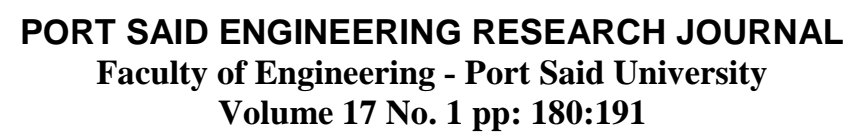

\title{
Mechanical Failures Risk Analysis and Implementation of Procedures to Reduce Incidents Onboard Offshore Supply Vessels
}

\author{
Mahmoud. M. Abbas ${ }^{a}$ and Khaled M. Abou Bakr ${ }^{b}$ \\ a Marine Engineering Technology Department, b Nautical Department, \\ College of Maritime Transport and Technology \\ Arab Academy for Science, Technology and Maritime Transport \\ P.O. Box: 1029, Alexandria, Egypt \\ a mahmoudmabbas@yahoo.com b khbakr eyahoo.com
}

\begin{abstract}
Among the various causes that lead to collisions between offshore supply vessels and installation stands out mechanical failures as the third from top with a percentage of 13\% according to the Gulf of Mexico collision incidents database in the period 1996 - 2009. Mechanical failures are often the direct outcome of bad maintenance, bad operation or human errors. This paper studies the types of mechanical failures that occur on board offshore supply vessels and presents a consequence analysis of some sample incidents that took place in the Gulf of Mexico in the period 1996-2009 in order to come up with practical recommendations that would help to reduce incidents from taking place or mitigate their negative effects.
\end{abstract}

\section{INTRODUCTION}

In 2005, twenty two fatalities and the toral destruction of a platform were the result of a collesion between Mumbai (Bombay) High North Platform and the supply vessel Sagar Suraksha [1]. The collision was proved to be a result of mechanical failure as well as bad,weather. Such an example of incidents caused by mechanical failures onboard Offshore Supply Vessels (OSVs) represents a hazard to the vessel, offshore installations, their crews and operations; thus, mechanical failures- both their causes and consequences- are worthy of inspection. Engine shutdown of OSVs during maneuvering, had to be thoroughly studied and investigated to come up with substantial findings. In fact, the shutdown is sudden in most cases and thus the results usually lead to great loses.

This paper uses the Gulf of Mexico collision incidents database as a case study. The Gulf of Mexieo was chosen for three reasons which could be prioritized as follows: 1Availability of information, 2- Being one of the world's largest and busiest production areas, 3 - The occurrence of a significant number of incidents in that area

After statistically surveying the incidents in the selected years 1996-2009, mechanical failures proved to be the second largest cause of them since a total of 29 accidents out of the 226 accidents that occurred were caused by mechanical failures as illustrated in figure 1

The most significant causes behind mechanical failures were collected from various sources and illustrated with examples. Hence, to study the consequences of collision incidents originated because of mechanical failures, risk analysis of consequences had to be signified.

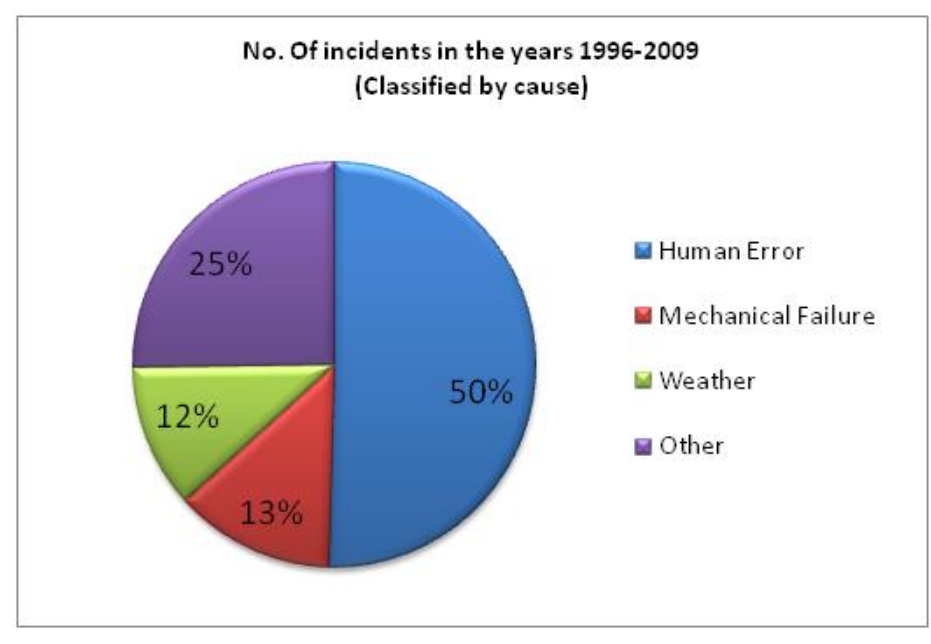

Figure 1 No of incidents in the year 1996-2009

\section{Risk Analysis Methodology selection}

Risk management is the process of assessing risk and developing strategies to manage it. Strategies include transferring the risk to another party, avoiding (preventing) the risk, reducing (mitigating) the negative effect of the risk, and accepting some or all of the consequences, as low as reasonably practicable (ALARP) of a particular risk. It should be noted that risk assessment forms a fundamental part of the risk management process. Risk Assessment is the process of gathering data and synthesizing information to develop an understanding of the risk of a particular enterprise and this conducted via risk analysis as illustrated in figure 2 . 
Risk analysis techniques are various and they are generally divided into qualitative and quantitative techniques. Due to the difficulty of obtaining numerical information about incidents, qualitative techniques are often used and the most common of these include: Hazard and Operability Analysis (HAZOP), Fault Tree Analysis (FTA), Event Tree Analysis (ETA), Preliminary Hazard Analysis (PHA), Failure Modes, Effects and Criticality Analysis, (FMECA). Failure Modes and Effects Analysis (FMEA), and finally Risk Matrix, although it is considered semi-quantitative. For suitability reasons, Event Tree analysis was chosen and implemented by the paper presenters. Event Tree Analysis (ETA) is a logical representation of the various events that may follow from an initiating event (e.g. a component failure). It uses branches to show the various possibilities that may arise at each step. It is often used to relate a failure event to various consequence models. It may also be used to quantify system failure probabilities, where several contributory causes can only arise sequentially in time. Construction starts with the initiating event and works through each branch in turn. A branch is defined in terms of a question (e.g. 'Protective device fails?'). The answers are usually binary (e.g. 'yes' or 'no'), but there can also be multiple outcomes (e.g. $100 \%, 20 \%$ or $0 \%$ in the operation of a control valve). Each branch is conditional on the appropriate answers to the previous ones in the tree [3].

Usually an event tree is presented with the initiating events on the left and the outcomes on the right. The questions defining the branches are placed across the top of the tree, with upward branches signifying 'yes' and downward ones for 'no'. The event-tree method is used to identify the probabilities of accidental scenarios leading to, for example, collision, an explosion, a pool fire or a jet fire etc. The frequencies of most events in the event-tree can be quantified in the usual way based on historical data [4].

To better understand the reasons behind mechanical failures onboard OSVs, a very brief of overview of OSVs including their types and work nature has to be presented. OSVs are a necessary part of the oil/gas production cycle. OSVs are generally expected to perform various diverse operations such as transferring crews, cargo and anchor handling, towing operations, storing hardware such as drill pipes and consumables for offshore exploration and production activities (such as, drilling fluids, bulk mud and cement, potable water, fuel, chemicals, etc), and finally conducting emergency response roles such as fire fighting, standby and rescue, and anti-pollution are also added, in various degrees, on to the already multifunctional role [5]

OSVs have many types; the most eminent of these are Anchor Handling Towing (AHT), Anchor Handling Towing Supply (AHTS), Platform Supply Vessel (PSV), Construction Support Vessel (CSV), Multi-purpose Supply Vessel (MPSV) and Fast Supply Vessels (FSV) [6] .Different mechanical failures occur according to vessel type as illustrated in the next section. $\bullet$

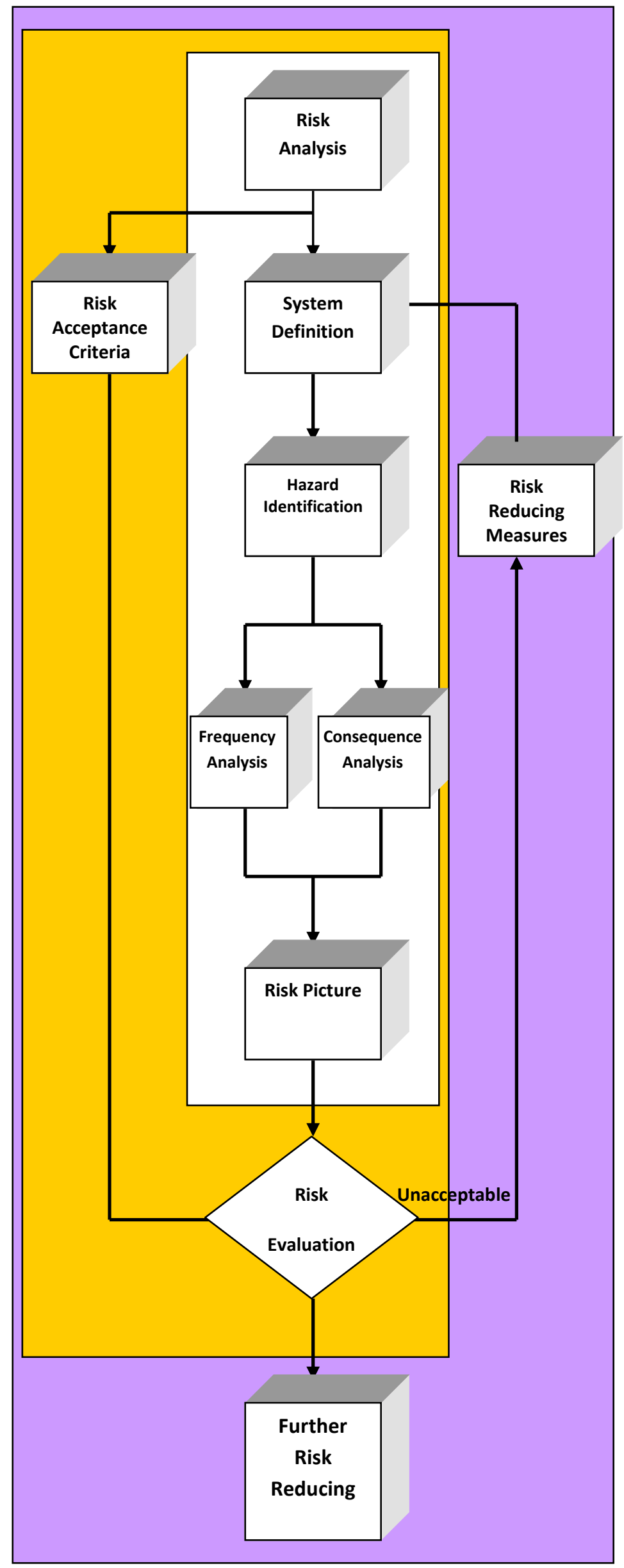

Figure 2: Iterative loop for risk assessment and risk control 


\section{Most Common Troubles that Occur in OSVs Machinery and Steering Gear}

OSVs machinery installations have two principal sources of excitation: the main engine(s) and the propeller(s). The two components are essentially linked by elastic shaft systems and may also embrace gearboxes and elastic couplings. The whole system is supported in flexible hull structures [7]. As this system goes into action, it becomes exposed to malfunctions that may affect operation integrity.

The following are examples of these malfunctions ordered according to their importance: Engine Running Failure, Engine Control Failure, Electrical source Failure, Clutch Failure, Steering Control Failure, Thruster Failure, Dynamic Positioning (DP) and Anchor Failure [8].

These malfunctions will be analyzed to stand upon the main causes behind them as well as the consequences that they have on operation; such analysis will be carried out by inspecting the Gulf of Mexico incidents database as follows:

\section{1) Engine Control Failure*}

The engine control system integrity is considered to be equally important to integrity of the main engine itself as the main engine is usually unmonitored by the crew during operation; thus, the engine control system covers for the monitoring even if the engine room is unmanned.
OSVs engine functions are controlled by the engine Control System which is mounted on the engine. The control system is dedicated and optimized for certain functions. It also communicates all machinery to increase the performance of OSVs operation and protect the ship from engine failures [9]

During operation some failures may occur in the engine control system and these could lead to emergency shutdown or malfunction such as: Low control air pressure, Rpm sensor failure, proportional valves stuck, water in air, bad feedback signal, short in control connection [10].The following event tree presents an illustration of an incident that occurred on the $14^{\text {th }}$ of October 1996 at the Gulf of Mexico; area: Garden Banks when a 166-ft supply workboat lost air pressure to its vessel controls resulting in loss of maneuverability. The vessel drifted into the floating drilling rig, sustaining a hole in the diesel fuel tank. A total of 1,000 gallons of diesel fuel was spilled. The rig sustained a 4x20 inch indentation to a column, which was determined to be cosmetic only. The event tree analysis proved the relation between low air pressure as initiating event leading to engine control failure on one hand and the occurrence of collision that resulted in spilling 1000 gallons of diesel fuel as final outcome.

*Note:

The study did not analyze all factors that may lead to the emergency shutdown of the main engine due to space limitations and so that attention may be given to other equally important factors that also lead to failure in the mechanical system and this is the employed analysis methodology for the rest of the failures.

Example:

Rig: Diamond Voyager $\quad$ Date: 14 October $1996 \quad$ Location: Gulf of Mexico, Garden banks $\quad$ Operator: Enserch Exploration, Inc

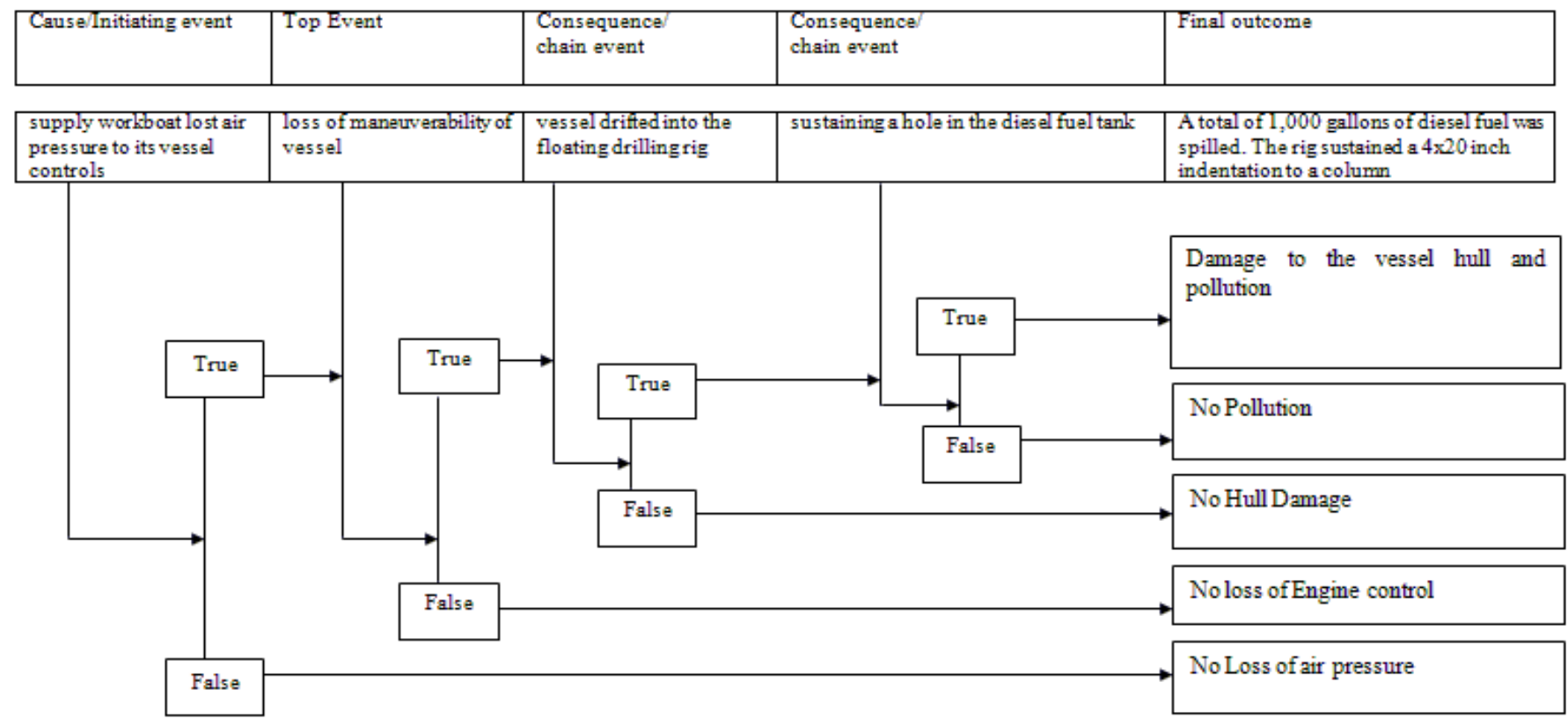




\section{2) Engine Running Failure}

All OSVs engines are protected by safety devices; these devices are used to protect engines from any failure that could happen during operation; especially that the engine room for most OSVs is unmanned.

The most important factors that lead to emergency main engine shutdown are: Low fuel pressure, low control air pressure, water in fuel, bearing temperature, crank case pressure, over speed, water temperature, exhaust temperature, T/C failure, speed governor Failure, fuel rack stuck [11]
The event tree analysis presented the sequence of events starting with low lube oil pressure passing by engine failure and resulting in the occurrence of collision that befell damage less than $25000 \$$.

\section{Example:}

Rig: A Date: 4 August $2000 \quad$ Location: Gulf of Mexico, Ship Shoal Operator: Murphy Exploration \& Production
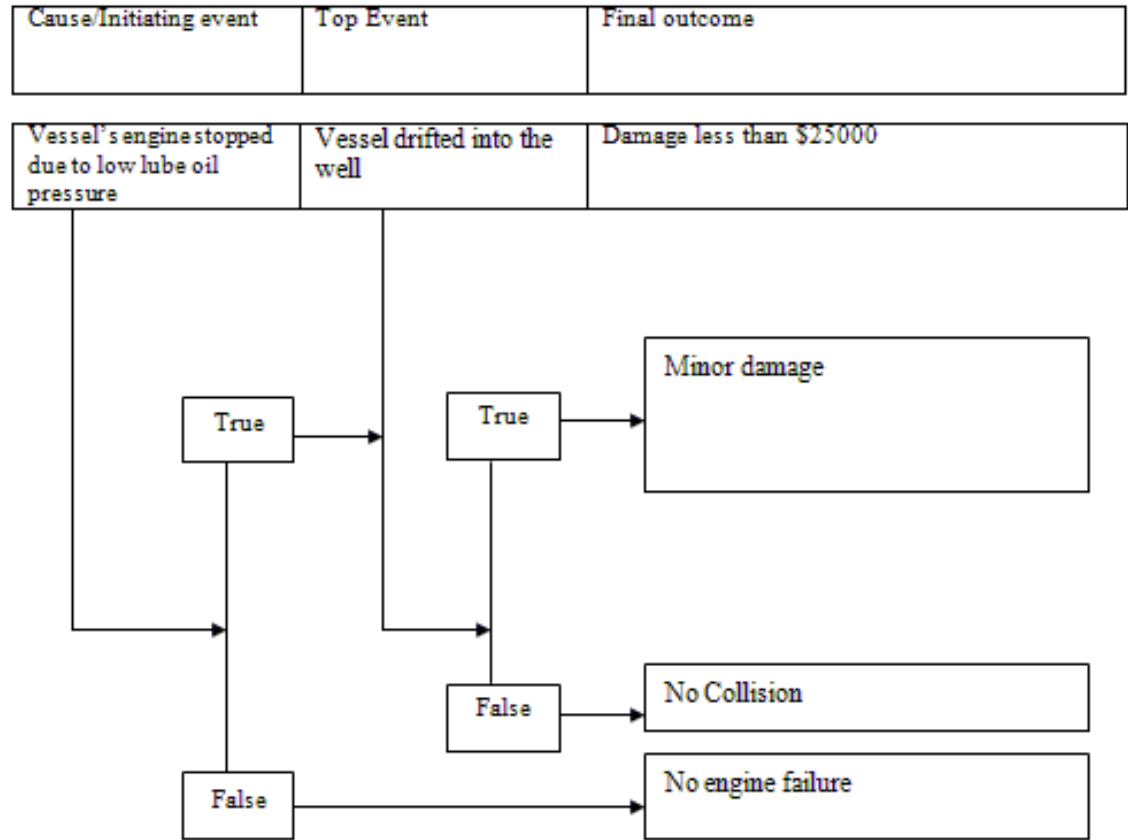

Figure 4: Event tree analysis for collision incident consequences caused by Engine failure 


\section{3) Electrical Failure}

OSVs are equipped by electric diesel generators in order to produce electric power. The produced electric power has many usages on board the vessel such as lighting, operating different pumps, cranes, navigation and control equipment as well as other usages. The electric power should be isolated for crew safety and for protecting the ship from any serious damage or failure that could happen.
During generating electric power, many sudden malfunctions may occur and these may hinder the generation process. These malfunctions may be defined as mechanical whether being from the electric generator engine or the generator itself such as: Earth, Short circuit, Open circuit, Generator engine failure, Alternator failure, Bad Insulation, Low current, Low frequency, High voltage, Circuit barker failure, Automatic control failure [12]. The event tree analysis highlights the dangerous effects of electrical failures that in such case led to 900000 \$ damage when vessel Diamond Ocean Saratoga's two generators tripped offline.

Example:

Rig: Diamond Ocean Saratoga Date: 22 August $2004 \quad$ Location: Gulf of Mexico, West Cameron (WC)

Operator: LLOG Exploration

\begin{tabular}{|c|c|c|c|}
\hline Cause/nitiating event & Top Event & $\begin{array}{l}\text { Consequence/ } \\
\text { chain event }\end{array}$ & Final outcome \\
\hline $\begin{array}{l}\text { both of the generators on } \\
\text { the boat tripped off line }\end{array}$ & $\begin{array}{l}\text { CP control system } \\
\text { automatic fail safe function } \\
\text { caused the props to reverse } \\
\text { pitch }\end{array}$ & $\begin{array}{l}\text { boat struck the port sponson directly } \\
\text { on the bow at approximately } 10 \text { knots }\end{array}$ & $\begin{array}{l}\text { The sponson crushed in approximately } 30 \% \text { of its } \\
\text { diameter, the upper structural braces were bent and } \\
\text { the lower support frame was pulled away from the top } \\
\text { of the hull tearing a hole approximately } 2 \text {-inch in } \\
\text { diameter into the top of the pontoon above the No.1 } \\
\text { ballast tank }\end{array}$ \\
\hline
\end{tabular}

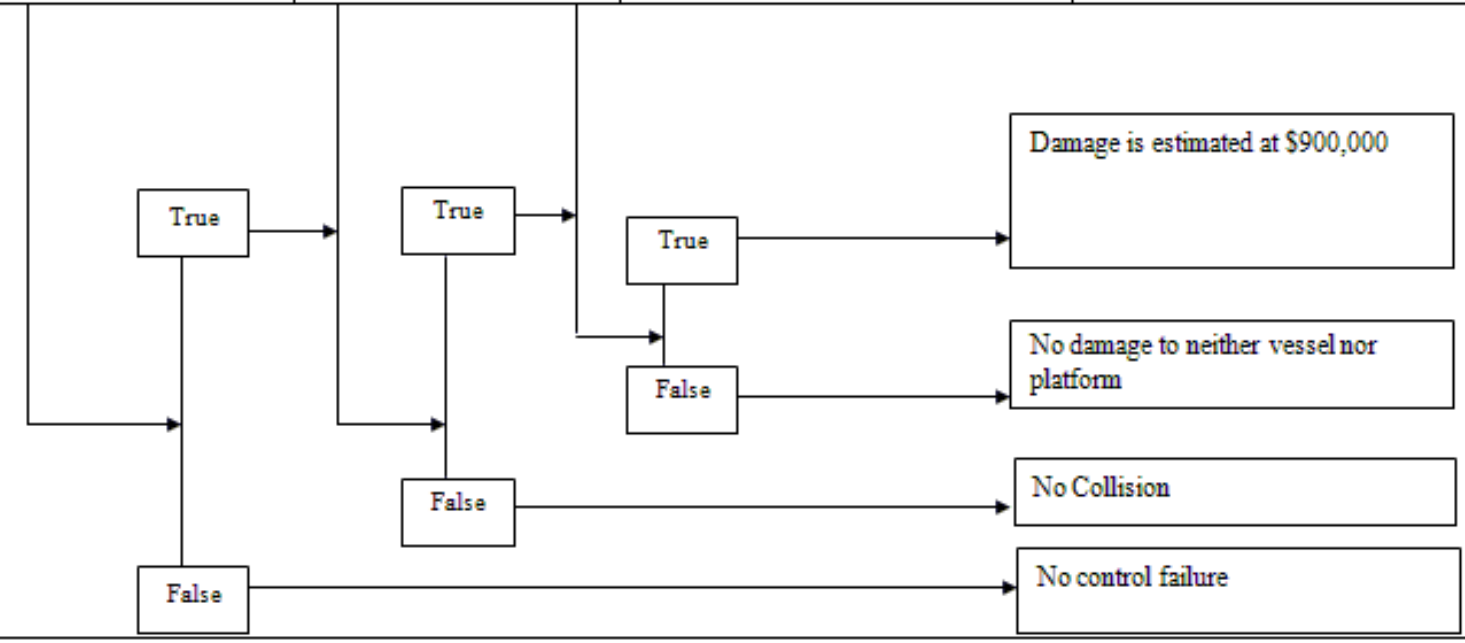

Figure 5: Event tree analysis for collision incident consequences caused by Electrical failure 


\section{4) Clutch Failure}

In all OSVs the main engine is always of the medium or fast speed, so it is necessary to use a gearing system between the main engine and the propeller and this is namely the clutch

The most common form of indirect drive of a propeller features one or more medium speed four-stroke engines connected through clutches and couplings to a reduction gearbox to drive either a fixed pitch or Controllable pitch propeller (CPP) [13].
When the main engine is geared up with the propeller, some malfunctions may occur such as: Low control air pressure, low oil pressure, bad signal, clutch control failure, misalignment and low engine speed [14].

The event tree analysis shows how collision was the direct result of clutch failure as it led to $\mathrm{M} / \mathrm{V}$ losing power to starboard and the final outcome was the spilling of 200 gallons of diesel fuel.

\section{Example:}

Rig: F Date: 16 April $2001 \quad$ Location: Gulf of Mexico, South Timbalier Operator: J. M. Huber Corporation

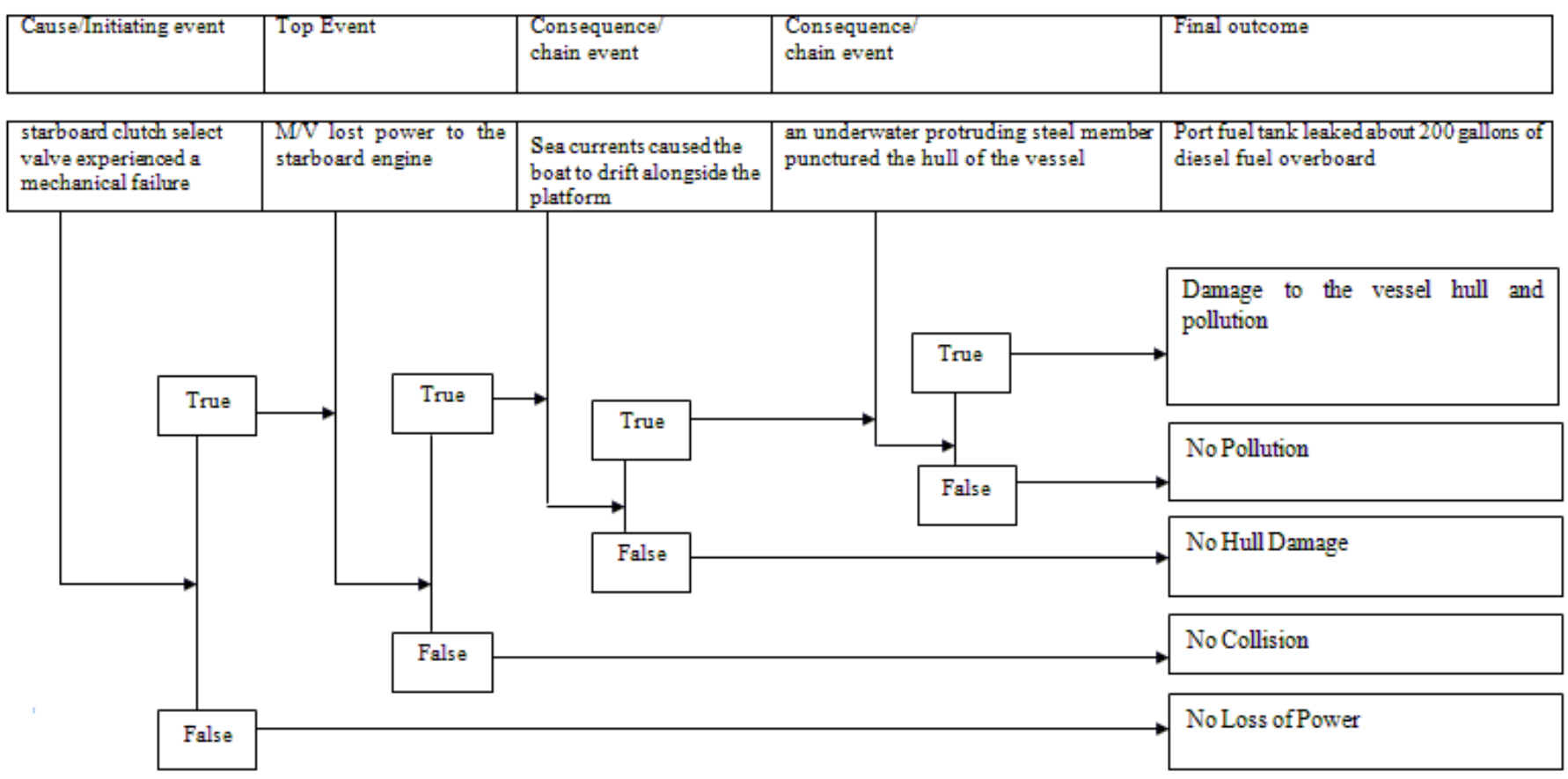

Figure 6: Event tree analysis for collision incident consequences caused by clutch failure 


\section{5) Steering system Failure}

The steering system is one of the most important systems onboard vessels due to its accuracy. OSVs are maneuvered from their bridges. Steering systems are used to pass the signal from bridge to steering equipments to control the ship during maneuvering; nowadays many different steering systems are used in OSVs to reduce collision [15].
During OSVs maneuvers, many failures may occur to the steering system which may pose danger to the integrity of vessel and operation and these may be: Loose signal from bridge, no feedback signal, low oil pressure, CPP not working, pumps no working, oil relief valve opened, low oil level, pneumatic control line failure [16]. The following event tree analysis detects how steering system failure resulted in collision and platform damage.

Example:

Rig: A-2 Date: 20 April 2009 Location: Gulf of Mexico, Vermillion Operator: Apache Corporation

\begin{tabular}{|l|l|l|l|l|}
\hline Cause/Initiating event & Top Event & $\begin{array}{l}\text { Consequence/ } \\
\text { chain event }\end{array}$ & $\begin{array}{l}\text { Consequence/ } \\
\text { chain event }\end{array}$ & Final outcome \\
\hline
\end{tabular}

\begin{tabular}{|l|l|l|l|l|}
\hline $\begin{array}{l}\text { pneumatic control line for } \\
\text { the forward/reverse gears } \\
\text { parted }\end{array}$ & $\begin{array}{l}\text { backward motion was not } \\
\text { arrested }\end{array}$ & $\begin{array}{l}\text { striking platform at riser } \\
\text { guard for Marathon } \\
\text { pipeline }\end{array}$ & $\begin{array}{l}\text { Jacket guard received puncture to vertical } \\
\text { riser and some pipes were bent }\end{array}$ & Damage cost \$33,000.00 \\
\hline
\end{tabular}

parted pipeline

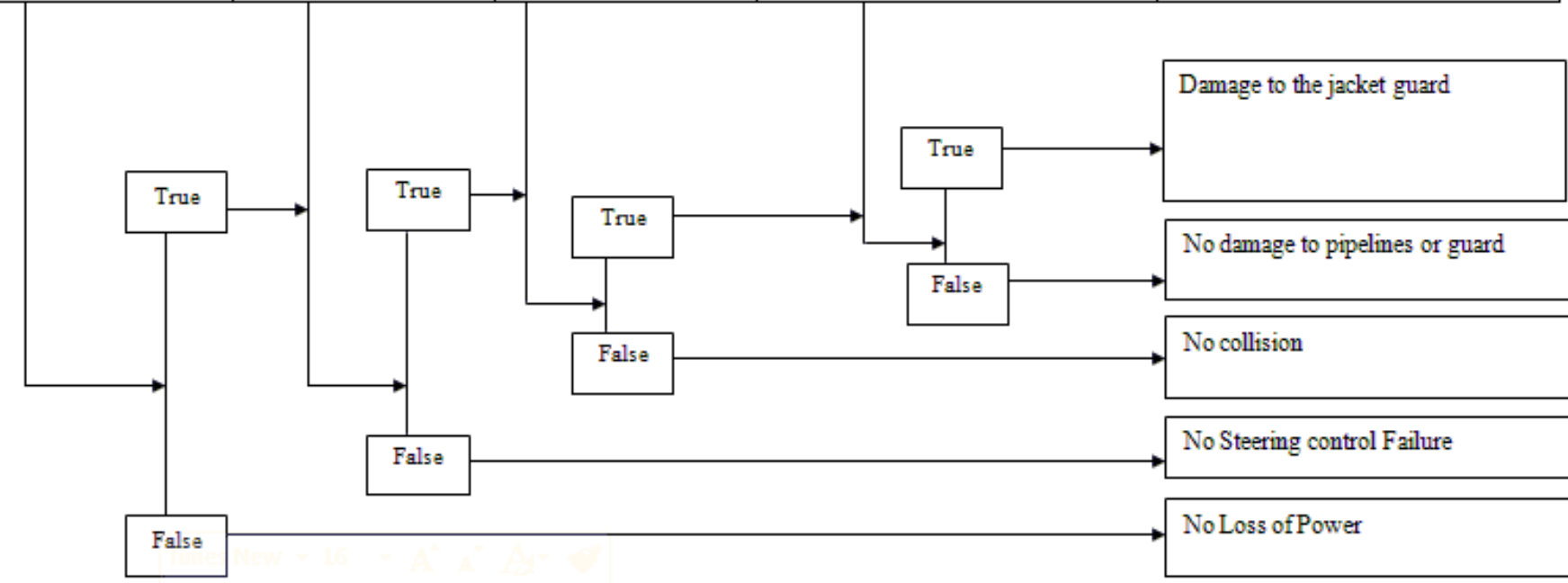

Figure 7: Event tree analysis for collision incident consequences caused by Steering control failure 


\section{6) Thruster Failure}

Because of the sensitivity of OSVs maneuvers both bow and aft thrusters are employed to increase the maneuverability. Advanced OSVs use bow thruster for increasing the performance of maneuvering, these thrusters may be operated by electric power or hydraulic power; bow or aft thrusters are not used during sailing but used during maneuvering only [17].
During maneuvers, thrusters could face various malfunctions due to technical causes such as: Low electric power, bad signal, low oil pressure, bearing stuck, missing Blade, broken blade earth and bad contactors [18]. The below event tree gives an example of how a failure of the bow thruster of M/V San Miguel led to damage to the vessel itself after colliding with rig ENSCO 81 resulting in damage to the rig as well as pollution.

\section{Example:}

Rig: ENSCO $81 \quad$ Date: 21 March $2007 \quad$ Location: Gulf of Mexico, VR (335) Operator: Murphy Exploration \& Production Company - USA

\begin{tabular}{|l|l|l|l|}
\hline Cause/Initiating event & Top Event & $\begin{array}{l}\text { Consequence/ } \\
\text { chain event }\end{array}$ & Final outcome \\
\hline
\end{tabular}

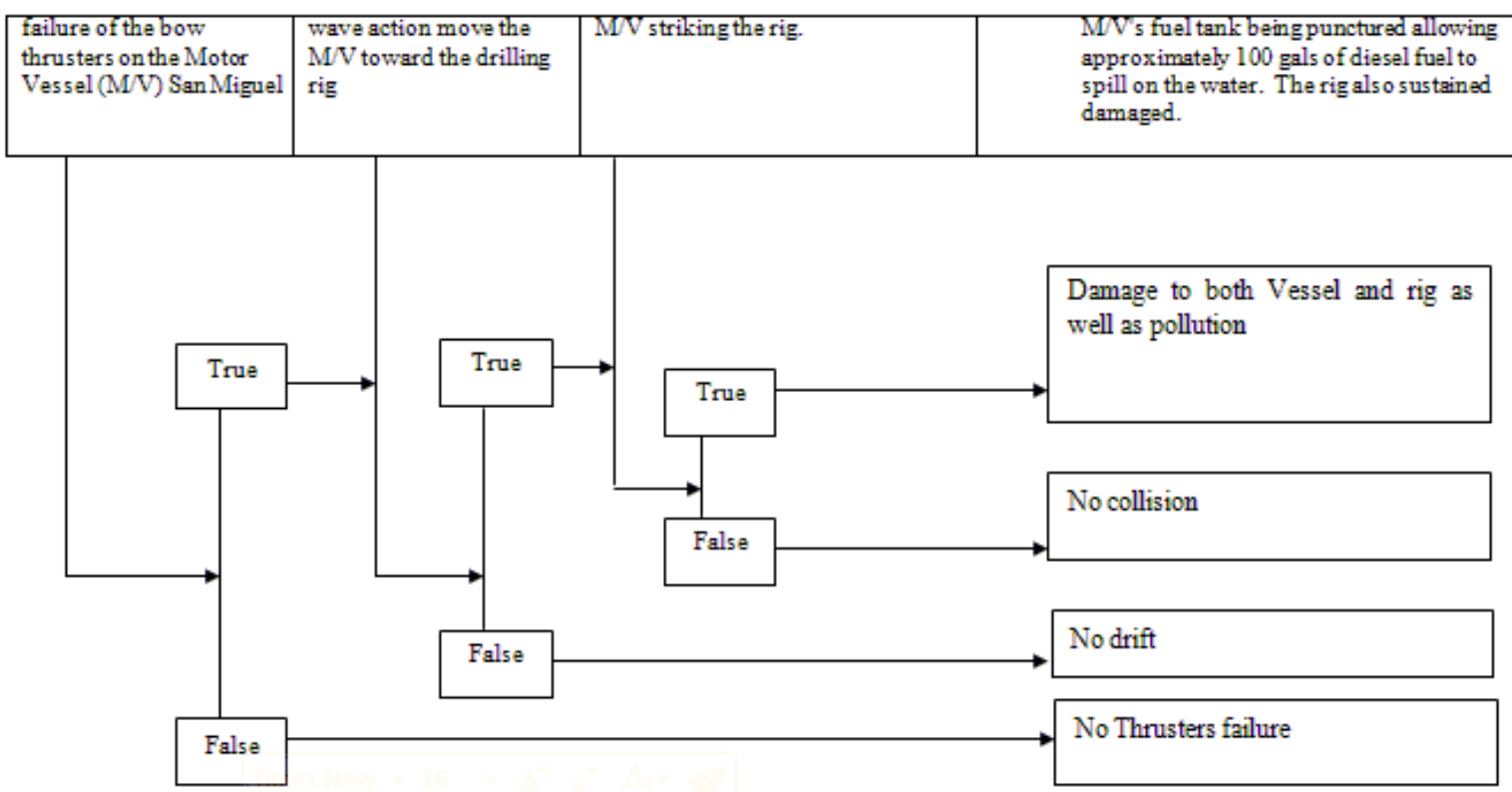

Figure 8: Event tree analysis for collision incident consequences caused by thruster failure 


\section{7) Dynamic Positioning (DP) Failure}

Offshore Oil production revolution increased day by day. One of the greatest techniques used in offshore production is Dynamic Positioning (DP). These types of OSVs are used to keep the ship in position during the job even in rough weather by keeping the engines and thrusters running according to GPS signal [19].

Example:

Rig: NABORS SUPER S.D. XIX Date: 7 May $2008 \quad$ Location: Gulf of Mexico, MC (1) Operator: TOTAL E\&P USA, INC
Amidst the different operations carried out by such special type of OSVs, mechanical malfunctions may occur in the main or secondary thrusters; in addition to malfunctions resulting from poor communication with satellites and these include: $M / E$ emergency stop, G/E emergency stop, thruster failure, Gyro failure, computer system failure, feedback signal failure, control air failure, wind sensor failure, speed sensor failure, Global Positioning systems failure [20]. More than $\$ 25000$ repairs was the result of collision of DP OSV with platform initiated by loss of dynamic positioning as explained in the event tree below.

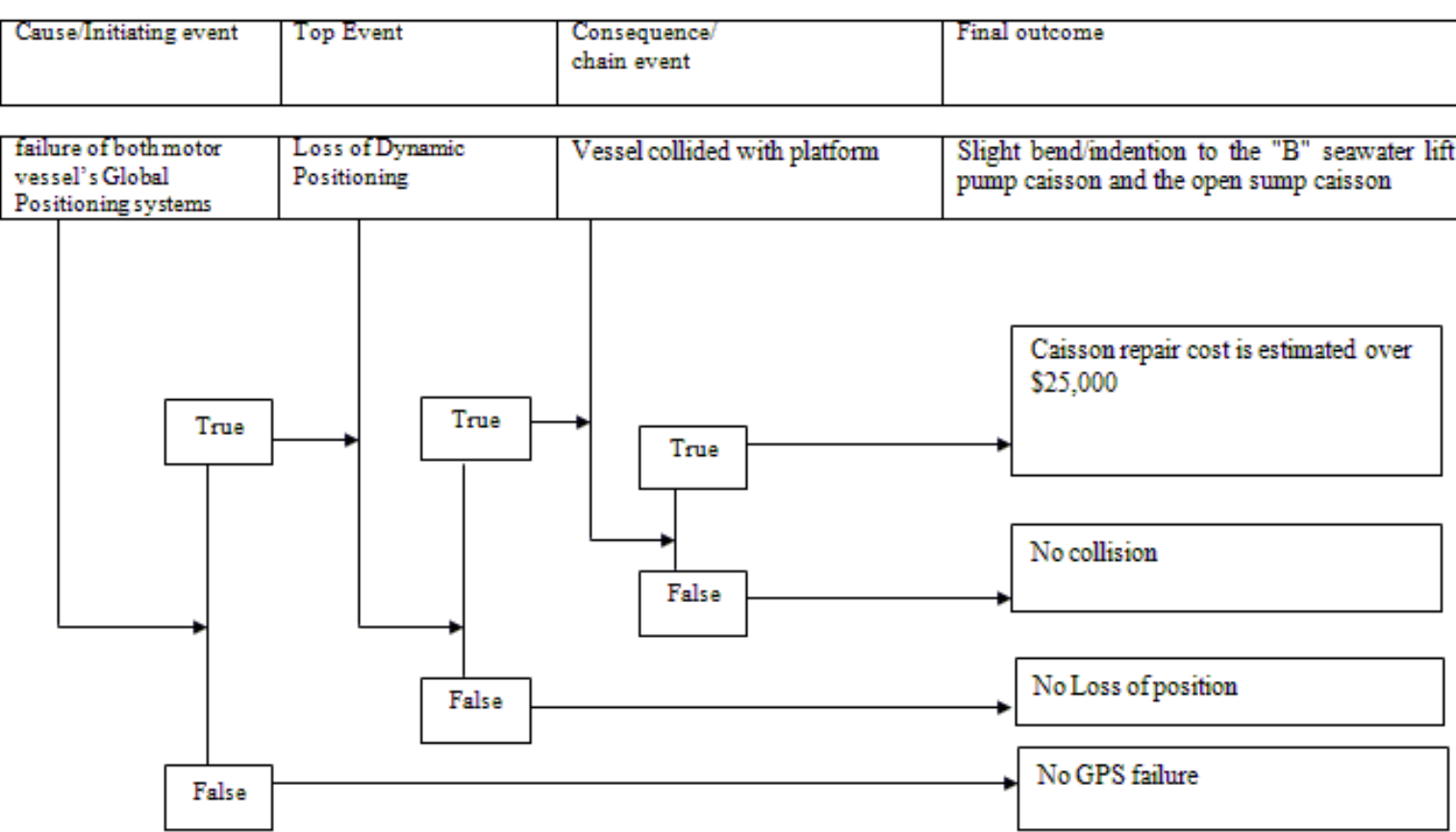

Figure 9: Event tree analysis for collision incident consequences caused by DP failure 


\section{8) Anchor Failure}

Anchors are used to keep the position of OSVs during engine stop, then the anchor is released from the ship by its gravity weight and later lifted by a windlass, most of OSVs anchors are connected to a windlass by steel wires instead of anchor chains used for traditional ships to save weight [21].
While operating with anchors, some mechanical problems appear and they may be: Windlass motor failure, hydraulic pump failure, operating handle stuck, windlass brake failure, oil leak, low oil pressure [22]. The following event tree presents an illustration of a collision incident caused by an anchor breaking; the event tree presents the sequence of events following the initial cause and their consequences.

Example:

\begin{tabular}{|l|l|l|}
\hline Cause/Initiating event & Top Event & Final outcome \\
& & \\
\hline
\end{tabular}

\begin{tabular}{|l|l|l|}
\hline Vessel anchor broke & $\begin{array}{l}\text { Vessel drifted into the } \\
\text { structure's helideck and } \\
\text { quarters }\end{array}$ & Damage less than \$25000 \\
\hline
\end{tabular}

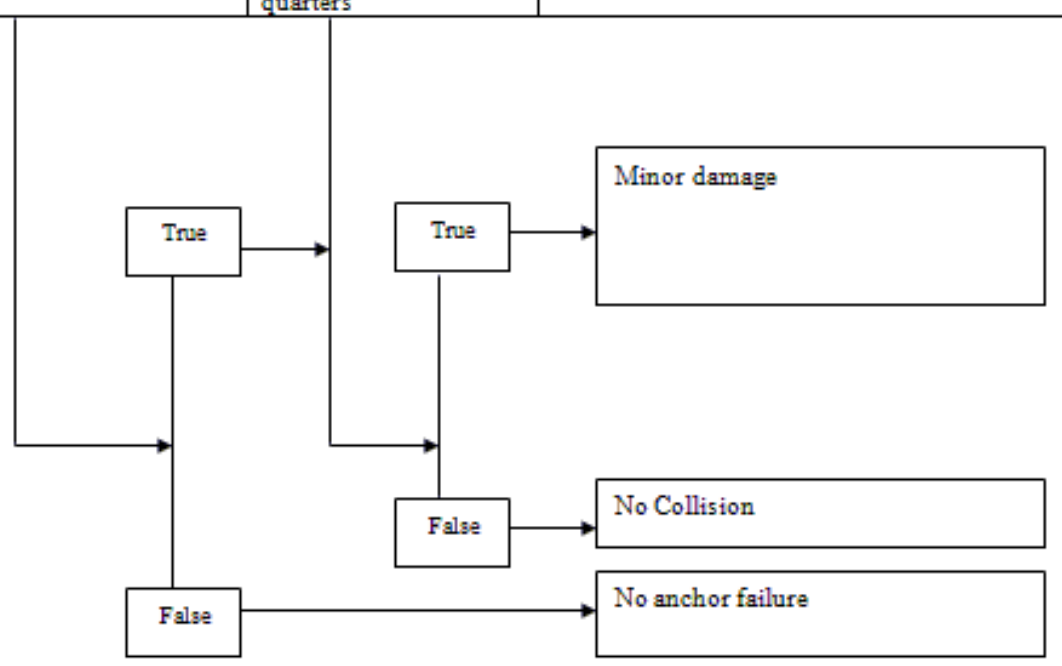

Figure 10: Event tree analysis for collision incident consequences caused by anchor failure 


\section{Discussions and Recommendations}

Analytical studies in this research paper have proved that mechanical failures are one of the main causes of collision between offshore supply vessels and offshore installations. A number of the most important causes of mechanical failure of machinery onboard OSVs have been investigated using the Event Tree methodology so as to avoid or mitigate the occurrence of such incidents the paper recommends the following:

1-Vessels that are less than 10 years of age should suffice with the annual accredited reports issued by international class societies. However, vessels that are 10 years of age or more must undergo thorough and detailed inspection by the flag state to determine the integrity and readiness of the vessel every 6 months similar to passenger vessels.

2-An evaluation should be done by manufacturer to all propulsion gears used in supply vessels as well as lighting equipment and towing machinery every 5 years and not to consider the reports issued by international class societies enough. The manufacturer's accredited report should be renewed every 5 years given that all maintenance plans were implemented as scheduled. This will decisively determine the technical state of such equipment.

3-Modern technologies should be employed to reassure that all maintenance plans set by manufacturer were implemented as scheduled as it has been discovered that some companies only renew paper work without actual work; therefore, it is important that maintenance processes of all equipment be documented via photography and video capturing supported by dates so as to be presented to flag state and international class societies for inspection annually or every 6 months according to vessel's age. 4-The capacity for more computer systems whose function is to monitor machinery and store any warnings for a complete year should be increased to reflect the efficiency of all machinery and proceed with maintenance as scheduled. These computers should be checked by flag state and international class societies annually or every 6 months according to vessel's age.

5-An online tracking system for all warnings should be developed by operator to allow monitoring the technical state of vessels daily and to intervene in such case the crew does not respond in proper time and to be acknowledged of the latest maintenance operations. One of the main causes of mechanical failures is the lack of skilled crew of officers, engineers and technicians due to the fact that they are usually recruited by operating companies and thus continuously altered in accordance. This leads to the loss of experience gained by crew after working on a specific vessel type; therefore, it is recommended that crews should stay aboard their vessels for longer periods to reduce mechanical failures.

6-The Quality control through 'International Safety Organization (ISO)' system that is applied to all maritime companies should strictly guarantee that all spare parts used in maintenance operations are original and accredited by manufacturer and not their lesser alternative. Purchasing receipts and serial numbers should be inspected carefully for each part before being installed on vessel.

7-When approaching platforms in bad weather, officers' orders for engine should be calculated thoroughly so as to give enough time for machinery to respond and not to overload them and consequently lead to a failure.

8-Officers should immediately respond to machinery alarms that appear on bridge and check with the responsible engineer without delay.

\section{References}

[1] http://oilrigdisasters.co.uk (28-04-2008)

[2] Vinnem, J. E, 2005. Offshore Risk Assessment Principles, Modeling and Applications of Quantitative Risk Assessment, (QRA) studies

[3] The Health and Safety Executive (HSE). (2006).Structural strengthening of Offshore Topsides Structures as Part of Explosion Risk Reduction Methods Prepared by: The Steel Construction Institute; Research Report 489.

[4] Shetty N.K., Soares C.G., Thoft-Christensen P., and Jensen F.M. (1998). 'Fire Safety Assessment and Optimal Design of Passive Fire Protection for Offshore Structures'. Reliability Engineering and System Safety, Vol. 61; 139-149.

[5] Ahmad Sarthy - Ship/Offshore Structures and Statutes, J. L. Ham - Ship/Offshore Engineering Systems American Bureau of Shipping - Pacific Division Kolb, OSV Singapore 2005 International Conference on Technology \& Operation of Offshore Support Vessels At the National University of Singapore, Republic of Singapore Modern Offshore Support Vessels Class and Statutory Perspectives

[6] LR-Fair play and Clarkson's Databases (year 2009)

[7] Lloyd's Register Rules and Regulations Part 3(ship structures) (2012)

[8] Doug Woodyard,2009.Pounders Marine Diesel Engines and Gas Turbine (ninth edition), Linacre House, Jordan Hill, Oxford OX2 8DP: ButterworthHeinemann

[9] Engine builder magazine issued (May 2012.)

[10] D.A.Taylor Butter Worths, 2005.Introduction to Marine Engineering ., Linacre House, Jordan Hill, Oxford OX2 8DP: Butterworth-Heinemann

[11] Rolls Royes control Manual for HSC (2010) page 46

[12] ABB Control Manual (2011) page 102

[13] Hundested propeller ,2010.Clutch propeller Shaft

[14] Wichita Marine Clutch manual Type MLI (2009)

[15] HD.McGEORGE,2001.Marine Auxiliary Machinery, Seventh Edition, , Linacre House, Jordan Hill, Oxford OX2 8DP: Butterworth-Heinemann

[16] Ram steering manual for Bright hub engineering manufacture ,(2012)

[17] Alan Hitchcox ,2005.Fluid-operated Clutch Enhances Bow Thruster

[18] Western marine electronic, bow thruster manual (2011),page 165 
[19] Annual DP Trails for Offshore by Germancher Lloyads 2011

[20] Golmar DP company, operation Manual (2011) page 87

[21] Klass,Van,Dokkum,2003.Ship Knowledge a Modern Encyclopedia, Netherlands,,Dokmar

[22] Blue ocean tackle for marine industry magazine (2012) page 33 